\title{
SUSTAINABLE ENVIRONMENTAL MANAGEMENT FOR INDIAN \& ASIAN LEATHER INDUSTRIES
}

\section{Dr. RAJAMANI S. ${ }^{1}$}

\section{Asian International Union of Environment Commission (AIUE), India}

With a view to overcome the challenges of salinity, sulphide oxidation in the effluent, disposal of hazardous category sludge \& other environmental issues faced by tanning industries in the world leather sector improved cleaner production, segregation of saline soak liquor and separate treatment, modified chrome recovery system and recovery of chromium \& sodium chloride salt in the form of powder and quality water with TDS less than 500mg/l for reuse by tanneries have been developed and are being implemented in the cluster of tanneries with Common Effluent Treatment Plants (CETPS). Physiochemical treatment is converted into total biological treatment with sulphide oxidation using enzyme and biomass which resulted in major reduction in terms of volatile organic matter and overall 50\% sludge generation from the effluent treatment plant.

Keywords: Cleaner Production, Leather Industry, Chrome Recovery, Effluent.

\section{Introduction}

World Leather Industries Sector process about 17-18 million tones of hides \& skins per year [1]. Only less than $20 \%$ of fresh hides and skins are processed without applying salt and more than $8-10$ million tones of salt mainly in form of sodium chloride is applied for curing and same is discharged as waste during the soaking process in tanneries. The environmental challenges faced by tanning industry are addressed by following applied Research \& Developments.

\section{Saline soak stream treatment and recovery of salt \& water}

Due to inherent quality of industrial wastewater such as textile dyeing units, tanneries etc., conventional treatment plants are unable to meet the

\footnotetext{
${ }^{1}$ S. RAJAMANI - Dr., Chairman-Asian International Union of Environment (AIUE) Commission, Old No. 18, New No. 45, First Street, South Beach Avenue, MRC Nagar, Chennai-600028, India, Mobile : +919840063210 Email : dr.s.rajamani@gmail.com
} 
prescribed TDS level of $2100 \mathrm{mg} / \mathrm{l}$ in the treated effluent. In addition to TDS management the control of volatile solids in hazardous category sludge is also becoming a necessity. For control of salinity, sludge and viable management of TDS, the treatment steps developed are (i) Cleaner production and other viable process control in tanneries, (ii) Segregation of saline soak and spent chrome liquors for separate treatment, (iii) Improved two stage biological treatment systems with better efficiency in BOD and COD removal, (iv) Minimum usage of chemicals in the treatment process and reduction in sludge generation, (v) Reduction in TDS level in the mixed stream and (vi) Tertiary treatment of the low saline mixed stream and integration of treated tannery effluent with treated domestic sewage wherever feasible for TDS management.

The segregated soak liquor after primary and secondary treatment further processed using Ultrafiltration (UF) \& Reverse Osmosis (RO) system for recovery of water and quality of saline stream for reuse in pickling. The balance treated saline stream is evaporated in Multiple Effect Evaporator and quality salt (98\% purity) is recovered for reuse [2].

The segregated chrome stream is taken for Centralized Chrome Recovery System (CCRS) for recovery of chromium in the form of chromium cake. In the improved chrome recovery system, the time required in chrome recovery process is reduced from $16 \mathrm{hrs}$ to less than $8 \mathrm{hrs}$. By avoiding the soak stream and supernatant from CCRS to main composite stream, the TDS level is reduced from $16000 \mathrm{mg} / 1$ to $8000 \mathrm{mg} / 1$.

\section{Improved common chorme recovery system (ccrs)}

The basic concept, design and development of improved CCRS comprises of the following:

- The segregated spent chrome liquor transported through tankers mounted on trucks with GPS and vacuum pumps;

- Separate collection tanks with screen chamber near CCRS for discharge of spent chrome liquor from tankers;

- Transfer of spent chrome liquor to main reactor for chrome precipitation by using suitable Alkali $(\mathrm{NaOH})$;

- Decanting of supernatant, clarification and distribute in tanneries for pickling;

- Dewatering of Chromium Hydroxide slurry and making it in the form of cake and powder, further process in to Basic Chromium Sulphate (BCS) for reuse in tanneries. 


\subsection{Chrome precipitation in main reactor using suitable Alkali chemical}

The equalized spent chrome liquor from the collection tank is pumped to Reactor. The Alkali dosing feed pump transfer the Alkali solution to Reaction tank. Alkali dosage is regulated by $\mathrm{pH}$ analyzer/transmitter with integrated controller. Depending on $\mathrm{pH}$ value in reaction tank Alkali solution feed pump speed will be varied to control the reaction. The agitator in Reaction tank ensures proper mixing of spent chrome liquor and alkali solution. Chromium present in chrome liquor precipitated as chromium hydroxide by increasing $\mathrm{pH}$.

Chemical reaction of a typical chrome recovery process is:

$$
\mathrm{Cr}_{2}\left(\mathrm{SO}_{4}\right)_{3}+6 \mathrm{NaOH}=2 \mathrm{Cr}(\mathrm{OH})_{3} \downarrow+3 \mathrm{Na}_{2} \mathrm{SO}_{4}
$$

\subsection{Separation of Chrome slurry \& Supernatant from the Main reactor}

In about 3-4 hours the chromium precipitates and settles as chromium hydroxide slurry in the bottom of the main reactor. The supernatants account for about 70 to $80 \%$ of the volume in the Reaction tank. After settling chrome slurry is separated by decanting supernatant from the top of the reactor. Chrome slurry from the bottom of the reactor is discharged by gravity into collection tank in the form of chromium hydroxide [3].

\subsection{Dewatering of Chromium Hydroxide slurry \& making it in the form of cake}

Chamber filter press is adopted to dewater the chromium hydroxide slurry and convert into chromium hydroxide cake. The solid concentration of the chromium hydroxide cake shall be about $30 \%$. At the end of filtration cycle, filter press is opened and chromium hydroxide cake is collected in a separate tray, shifted to storage yard. Chromium hydroxide cake is further processed and reused in the tanneries. The filtrate is collected in supernatant collection tank and then taken for further process and reuse. The overall schematic diagram [4] of the improved chrome recovery system is given below: 


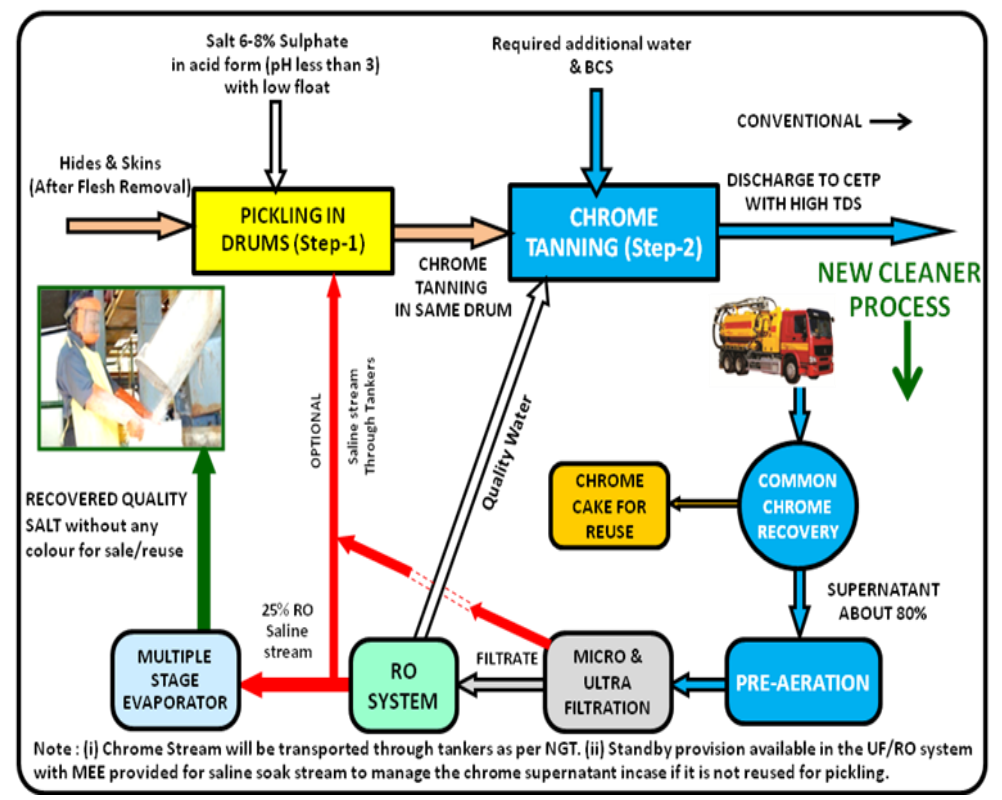

Figure - Chrome Stream Treatment, Recovery \& Reuse

\section{Integration of physiochemical system with biological treatment for sulphide oxidation}

With a view to oxidize sulphide present in effluent, control sludge settling in equalization tank and to minimize chemical usage equalization system has been upgraded with increased detention time, increased depth and usage of new type of aspirators integrated with compressor. The residual excess biosludge from secondary clarifier is pumped to equalization tank which is helpful in biological oxidation process and to reduce the chemical dosage in the first stage clarifier and reduction in sludge generation. The improved aeration system with jet aspirator has been successfully adopted in many effluent treatment plants [5]. The quality of effluent from biological treatment is fit for further treatment adopting UF\&RO system and recovery of water for reuse.

\section{Conclusion}

The conventional effluent treatment systems are being upgraded by segregating the saline soak stream with separate treatment, adoption of UF $\&$ RO and Multiple Effect Evaporators (MEE) with recovery of quality salt 
for reuse. These technological developments and upgradation of CETPs are being implemented in many locations covering more than 700 tanneries in India with financial outlay of more than 150 million US dollars.

\section{Acknowledgement}

Contributions of National Mission for Clean Ganga (NMCG), Department for Promotion of Industry and Internal Trade (DPIIT), National Green Tribunal (NGT), Asian International Union Environment (AIUE) Commission and other commission members from various countries, IULTCS, UNIDO, European Union including Italy, Spain, Netherlands and other Countries such as China, Romania, Turkey and Russian Federation, New Zealand are acknowledged.

\section{References}

1. S.Rajamani (2020), Sustainable ZLD System by Adopting Centralized Treatment of Segregated Streams for Recovery of Reusable Quality Chemical, Salt \& Water - First of its kind in India \& Asia - Article published in Leather News India Journal.

2. S.Rajamani (2019), Innovative Technologies on Cleaner Production and Waste Management in Tanneries - Paper presented in International Leather Engineering Congress Innovative Aspects for Leather Industry, Izmir, Turkey.

3. S.Rajamani (2018), Viable Environmental Technologies integrated with Cleaner Production - Sustainable Options for Global Leather Sector Paper presented in Innovative solutions for sustainable development of textile and leather industry - International Science Conference 2018, Oradea, Romania

4. S.Rajamani (2018), Sustainable Environmental Technologies Integrated with Cleaner Production - Recent developments in World Leather Sector Paper presented in XIV ${ }^{\text {th }}$ International Scientific-Practical Conference, UlanUde, Russia.

5. S.Rajamani (2016), Innovative Environmental Technologies including Water Recovery for Reuse from Tannery and Industrial Wastewater - Indian and Asian Scenario, Paper presented in 6th International Conference on Advanced Materials and Systems (ICAMS 2016), Bucharest, Romania. 